\title{
ASO Author Reflections: Diagnostic Significance of Extramural Venous Invasion in Patients with Locally Advanced Esophageal Cancer
}

\author{
Zohra Faiz, MD ${ }^{1}$, Gursah Kats-Ugurlu, MD, PhD², and John T. M. Plukker, MD, PhD ${ }^{1}$ \\ ${ }^{1}$ Department of Surgery, University of Groningen, University Medical Center Groningen, Groningen, The Netherlands; \\ ${ }^{2}$ Department of Pathology, University of Groningen, University Medical Center Groningen, Groningen, The Netherlands
}

\section{PAST}

The presence of tumor cells in blood vessels, particularly extramural venous invasion (EMVI), is an independent poor prognostic factor in colorectal cancer (CRC) ${ }^{1,2}$ The Association of Directors of Anatomic and Surgical Pathology and the College of American Pathologists define EMVI as the microscopic presence of tumor cells in venous vessels beyond the muscularis propria. ${ }^{3},{ }^{4}$ The prevalence and significance of EMVI in esophageal cancer (EC) is still unclear. Most studies focused on differentiating venous invasion from lymphatic vascular invasion (LVI), as expressed in the current TNM classification, without assessing where the venous invasion was located. Problems addressed included the prevalence and prognostic significance of EMVI in EC resection specimens, and how to overcome difficulties among pathologists in identifying EMVI by using Elastica van Gieson (EVG) staining. We investigated archival specimens with pathological $\mathrm{T} 3$ or higher from patients operated by surgery alone, and those after neoadjuvant chemoradiotherapy (nCRT). ${ }^{5}$ The key question was whether EMVI can be used as a predictive factor in the response evaluation of nCRT.

ASO Author Reflections is a brief invited commentary on the article, "Prevalence and Prognostic Significance of Extramural Venous Invasion in Patients with Locally Advanced Esophageal Cancer", Ann Surg Oncol. 2018;25:1588-1597.

(C) The Author(s) 2018

First Received: 23 October 2018;

Published Online: 31 October 2018

J. T. M. Plukker, MD, PhD

e-mail: j.t.m.plukker@umcg.nl

\section{PRESENT}

EMVI was present in one-quarter of EC patients after surgery alone, and in $21.6 \%$ of patients after nCRT, as confirmed by additional EVG staining. ${ }^{5}$ The prevalence of EMVI was significantly higher in mid-esophageal and squamous cell carcinoma. Although significantly higher in the presence of LVI, EMVI showed no significant correlation with pathological $\mathrm{T}$ and $\mathrm{N}$ stage. In the nCRT and surgery-alone groups, EMVI was scored higher in tumors with lymphatic invasion (75\% and $63 \%$, respectively) and perineural invasion (both 75\%). EMVI was shown to be a strong independent prognostic factor, with significantly shorter disease-free survival in the surgery-alone group with respect to EMVI-negative tumors. However, in the nCRT group, the presence of EMVI was not independently associated with survival. Based on these results, it seems necessary to differentiate EMVI from LVI in predicting prognosis. Therefore, pathologic reports should separately describe the presence of EMVI. Currently, EMVI can also be identified on diffuse-weighted (DWI) magnetic resonance imaging (MRI) in CRC patients. ${ }^{6,7}$

\section{FUTURE}

In future, EMVI should be investigated in a larger group of EC patients undergoing nCRT followed by surgery. Our results in the nCRT group are probably influenced by case mix and less power in a relatively small group with a potential selection bias of non-responders to nCRT. ${ }^{5}$ The value of EMVI as an independent predictor of response to nCRT remains questionable. To determine the impact of nCRT, we require accurate information about the presence of EMVI in the pre- and post-CRT setting. Therefore, we recommend investigation and correlation of EMVI in EC patients in ongoing or upcoming DWI-MRI studies. For a 
complete pathologic examination, separate reporting of EMVI in the EC resection specimens should be added. Moreover, as regression of EMVI after nCRT leads to vessel fibrosis and can be observed on MRI, it may be used as a predictive imaging marker in the response evaluation.

DISCLOSURES Zohra Faiz, Gursah Kats-Ugurlu, and John T.M. Plukker have no conflict of interest to disclose.

OPEN ACCESS This article is distributed under the terms of the Creative Commons Attribution 4.0 International License (http://crea tivecommons.org/licenses/by/4.0/), which permits unrestricted use, distribution, and reproduction in any medium, provided you give appropriate credit to the original author(s) and the source, provide a link to the Creative Commons license, and indicate if changes were made.

\section{REFERENCES}

1. Matsuda T, Kurokawa Y, Yoshikawa T, et al. Clinicopathological characteristics and prognostic factors of patients with siewert type II esophagogastric junction carcinoma: a retrospective multicenter study. World J Surg. 2016;40(7):1672-9.
2. Lagarde SM, Phillips AW, Navidi M, Disep B, Immanuel A, Griffin SM. The presence of lymphovascular and perineural infiltration after neoadjuvant therapy and oesophagectomy identifies patients at high risk for recurrence. $\mathrm{Br} J$ Cancer. 2015;113(10):1427-33.

3. Betge J, Pollheimer MJ, Lindtner RA, et al. Intramural and extramural vascular invasion in colorectal cancer: prognostic significance and quality of pathology reporting. Cancer. 2012;118(3):628-38.

4. McClelland D, Murray GI. A comprehensive study of extramural venous invasion in colorectal cancer. PLOS ONE. 2015;10(12):e0144987

5. Faiz Z, Huijgen LJW, Alqethami HJ, Burgerhof JGM, Kats-Ugurlu G, Plukker JTM. Prevalence and prognostic significance of extramural venous invasion in patients with locally advanced esophageal cancer. Ann Surg Oncol. 2018;25:1588-97.

6. Roxburgh CS, McMillan DC, Richards $\mathrm{CH}$, et al. The clinical utility of the combination of $\mathrm{T}$ stage and venous invasion to predict survival in patients undergoing surgery for colorectal cancer. Ann Surg. 2014;259(6):1156-65.

7. Messenger DE, Driman DK, McLeod RS, Riddell RH, Kirsch R. Current practice patterns among pathologists in the assessment of venous invasion in colorectal cancer. $J$ Clin Pathol. 2011;64(11):983-9. 